\title{
Moving Targets: \\ Photography and Its Metaphors
}

\section{Shoot! Existential Photography. The Photographer's Gallery, London, 12 October, 20 I 2-6 January, 2013.}

Shoot! Existential Photography. Clement Cheroux. Berlin: Revolver Publishing, 20 I0. Pp. I 19.\$29.24 (cloth).

Reviewed by Annebella Pollen, University of Brighton

Two years after its first appearance at the French photography festival Les Rencontres d'Arles, Clement Cheroux's Shoot! Existential Photography has been reconfigured for The Photographer's Gallery in London for 2012-13. The exhibition is based on a core premise: there is a fertile connection between the shared language and practices of the camera and the gun (e.g. "shooting," "aiming," and "loading"). In the book and the exhibition, this metaphorical connection is initially elaborated via a particular, once-popular European photographic novelty, the fairground shooting gallery, that allowed winning participants to trigger a photograph of themselves by hitting a bull's-eye with an air rifle. This side show, now nearly obsolete, first appeared in the years after the First World War and remained a popular attraction until the 1970s. Cheroux's fascination with it lies in the symbolic nature of selfdestruction inherent to the form. To trigger the camera's mechanism and win the self-portrait prize, the participant must symbolically take aim at him- or herself. The resulting image suggests self-annihilation, as the participant appears to hold a gun to him- or herself in a mirror. As Cheroux puts it in the accompanying publication, "The whole attraction plays with the temptation to fight a duel with oneself, with the thrill of being one's own executioner-for the sake of a quick peep into the vertigo of self-destruction" (9-10). Cheroux's faith in the particular existential nature of the technology is affirmed by the impressive roster of European avant-garde "celebrities" who participated in these shooting galleries. Through images of some of the most famous of mid-century photographers, film makers, and intellectual figures (among whom are Cartier-Bresson, Brassaï, Man Ray, Fellini, Truffaut, Deleuze, and most notably Sartre and de Beauvoir), Cheroux establishes visual connections
MODERNISM / modernity

VOLUME TWENTY,

NUMBER ONE,

PP 123-127. (C) 2013

THE JOHNS HOPKINS

UNIVERSITY PRESS 


\section{MODER N I S M / modernity}

I24 between photographic shooting galleries and, variously, the cultural violence of dadaism, surrealist interest in automatism, and philosophical ideas about being and nothingness. The latter part of the show features a range of more recent work by artists who have brought visual imagery and violence together even more explicitly. Steven Pippin, Rudolf Steiner, and Jean-Francois Lecourt use firearms to trigger their photographs (they shoot at the camera), Niki de Saint Phalle adopted a rifle as a paintbrush in her projectile paintings, and Christian Marclay assembles a montage of film footage of shoot-outs to expose the false glamour of Hollywood gun culture.

Both the exhibition and the accompanying publication suggest a powerful relationship between photography and destruction. Almost every image takes direct aim at the viewer as well as the sitter. Cheroux describes these confrontational acts as "photographic suicide" (89) and as reflections on "the mortal nature of the photographic gesture" (67). Cheroux's approach, for all of its novel subject matter, is indebted to a long-standing strand of cultural criticism that envisages photography as closely linked with death. From Susan Sontag's influential but nihilistic On Photography (1977) to Roland Barthes's famous Camera Lucida (1980)—the latter composed while the author was grieving the death of his mother-photographs are frequently described as memento mori, and photography itself is characterized as a medium of bereavement that is concerned with absence, loss, and death. More recent accounts have sought to critique this dominant, even intractable view. David Green, for example, is one of a number of writers who has expressed considerable exhaustion with what he describes as the "cloying melancholia of the post-Barthian era of photographic theory". ${ }^{1}$ In addition to replaying some tired ideas about photography and death here, Cheroux oversimplifies the apparent symbiosis between cameras and weaponry. Sontag's influence is evident. In her characteristically aphoristic writing style - a style that has no doubt contributed to her dominance over decades of photographic criticism despite the fact that she apparently did not like photography very much—she describes the camera as "the sublimation of the gun" and suggests that "to photograph someone is a sublimated murder." Yet even Sontag is hesitant to ascribe too much significance to this allusion. She states, "Despite the extravagances of ordinary language and advertising, [cameras] are not lethal. ...

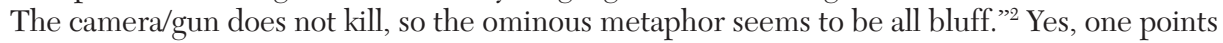
and shoots with both devices, but beyond that linguistic similarity, the fact remains that one technology disseminates missiles for destruction while the other lets in light to create an image. Substantial poetic licence is required to override these fundamental differences.

There is also room to be skeptical about the so-called existential character of most of the founding imagery in Shoot! Both the exhibition and the book lead with an image of de Beauvoir and Sartre at a Paris photographic rifle range in 1929. De Beauvoir, youthful in a trench coat and beret, appears charmingly vulnerable, holding the gun with both hands and with both eyes closed. Sartre, at her side and sporting spectacles, a pipe, and a formal three-piece suit, places a reassuring hand on her shoulder. This tender portrait is undoubtedly intriguing for its incongruous pairing of famous scholars and fairground guns, but it may not constitute a solid basis for the ostensible philosophical angle of the whole project. Cheroux states that his fascination with automated portrait technology began in a Paris flea market over twenty years ago, when he discovered a photograph of some unknown interwar figures aiming a gun at the camera. At the time, Cheroux did not know about carnival photographic rifle ranges, so he applied his own sinister significance to the image as a kind of mafia portrait. As the reappropriation of a vernacular photograph, this act reveals more about the basis of the show than any later lip service paid to existentialism. As a found photo, the flea market image initially offered enticingly sparse information about its origins, and like any other objet trouvé, its rediscovery and reuse opens it to a range of retellings that are quite separate from its former purpose. It could be argued that the destruction threatened in Shoot! is, in fact, the death of the author. Vernacular photographs are notoriously porous to projection and are ever-more frequently used as inspiration for artists and curators for this reason. In Shoot!, Cheroux has constructed a curatorial frame that fits his imaginative wishes, perhaps at the expense of the shooting gallery photographs' original meanings. It would inconvenience the angle of the exhibition and book to suggest that such images are less about ego-destruction and death and more about pleasure and play, but the latter description ultimately seems a better fit. 


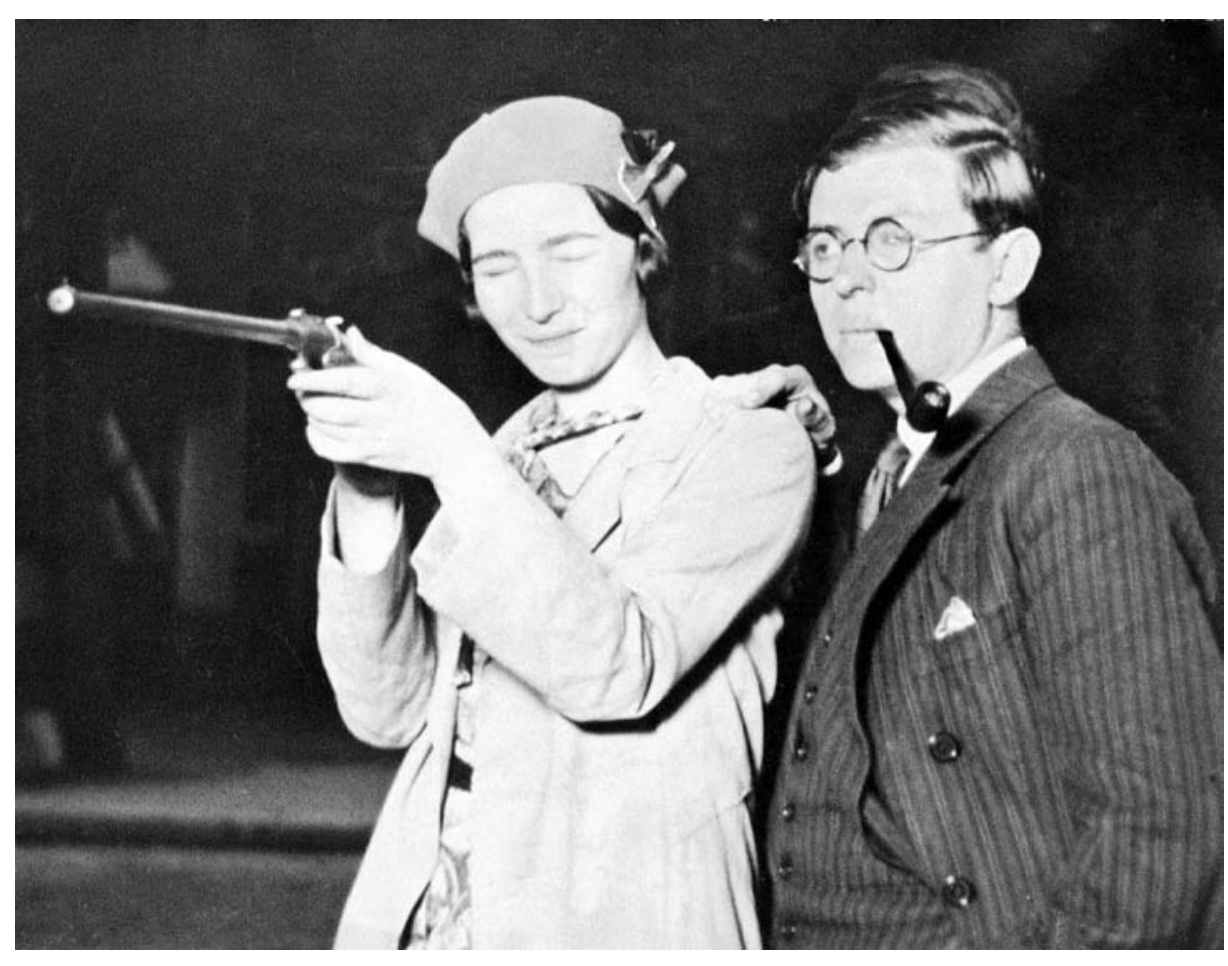

$\Delta$

Fig. I. Simone de Beauvoir, Jean-Paul Sartre

Photo-shot, fairground at Porte d'Orléans, Paris, June 1929

(C) Jazz Editions / Gamma / Gamma-Rapho

Courtesy of The Photographers' Gallery, London

Despite the sometimes ill-fitting curatorial angle, the exhibition has plenty to recommend it. The centerpiece of the show, entitled In Almost Every Picture \#7, is a fascinating sequence of photographs assembled by noted vernacular photography collector and curator Erik Kessels. These photographs capture Dutchwoman Ria van Dijk at photographic shooting galleries over eight decades, beginning in 1936 (when van Dijk was sixteen) and continuing through the present day. Van Dijk, now in her nineties, continues to record herself at her local biannual fair, now with television crews and a "fan club" in attendance. In these scaled-up reproductions, framed in the sweetest of candy floss colors, van Dijk forever takes up a gun in her left hand and pulls the trigger with her right, all the while pursing her lips and looking carefully through the viewfinder with a single determined gaze. These photographs document continuities and changes over time with remarkable perspicuity. Clothes and hairstyles reflect shifting eras, as do the paraphernalia of the fairground backdrop, which evolve over the years into space-age arcade games and garishly colored, plush toys. Technology also evolves, shifting from black-and-white to Polaroid prints, yet van Dijk always assumes the same position in almost every picture.

There is little here to suggest an enduring battle with the ego or photographic suicide. These are photographs of endurance and resilience, of ritual and commemoration. As is the case with most forms of popular, "non-artistic" photographs, these photographs present a visual conundrum only to those not included within their immediate circle of communication. To those inside the circle, its function is clear: the image is a prize and represents a cause for celebration. One shooting-range photograph, taken in Blackpool in 1935, reveals that the practice was sold not as an opportunity to annihilate oneself but as a chance to display ability and prowess; on the back of the photograph is a claim that it provides "proof of the marksman shooting the bull." 


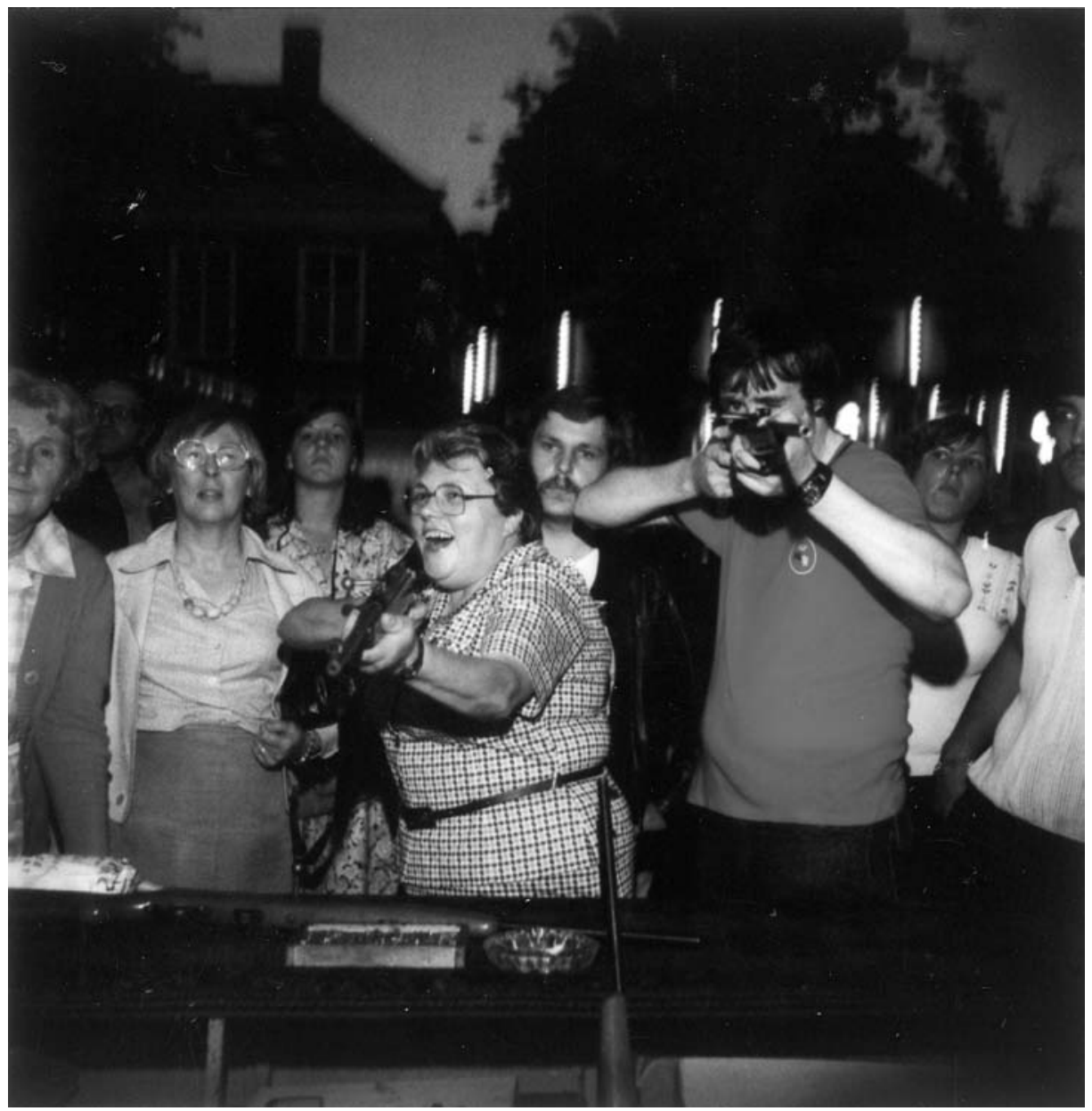

$\Delta$

Fig. 2. Ria van Dijk

Photo-shot, Oosterhout, Netherlands, 1978,

Polaroid, $10.8 \times 8.8 \mathrm{~cm}$

(c) Erik Kessels. Courtesy Stedelijk Museum, Amsterdam

Courtesy of The Photographers' Gallery, London

Original in color

Some rifle range portraits include place names and dates designed to appear in the frame, to reinforce their roles as democratic souvenirs of a carnival event. The indiscriminate gaze of the camera always allows for an excess of information, and this is particularly the case with the fairground pictures. Beyond the central image of the shooter and gun, partners clasp hands in anticipation of the winning shot, or they raise their eyebrows wearily at the show of bravado; friends share the focus by training tense sets of eyes at the target. Children watch and wait while the adults take aim, sometimes with fingers in ears. In one touching instance, a little girl to the side of the picture clutches a prize of her own: a goldfish in a plastic bag. In almost all of the photographs from the shooting ranges, whether from the 1920s or the 1990s, the shooter is pictured as part of a group. These photographs are trophies of collective events. One image, taken in 1994 in Karlsruhe, Germany, offers an alternative, extended family photograph in which the 
central, gun-toting player is surrounded by twelve figures, including grandmothers and babes in arms. These are life-affirming rather than life-denying photographs.

Given the show's relentless emphasis on photography as a kind of symbolic Russian roulette laced with existential anxiety - an emphasis compounded in the later sets of artists' images on the second floor - a remarkable amount of laughter rings throughout the gallery, not least in the popular re-creation of the shooting range at the close of show. For a few pounds, exhibitiongoers can take their own shot at a specially designed Photographer's Gallery target. Young and old alike line up to take on the challenge and to find, significantly, that it's not as easy as it looks.

Clement Cheroux has assembled a striking body of material for Shoot! It may be overdetermined theoretically, and it may not always cohere around his chosen concept, but he admirably brings a fascinating historic photographic novelty from sideshow to center stage. Sitters and viewers, photographs and cameras all come under fire in this confrontational and sometimes nihilistic show. Whether it is to demonstrate the death of the ego, the death of the author, or the death of photography itself, gallery goers are repeatedly shot at. In the final frame, however, they get a chance to fight back.

\section{Notes}

1. David Green, "Marking Time: Photography, Film and Temporalities of the Image," in Stillness and Time: Photography and the Moving Image, eds. David Green and Joanna Lowry (Brighton: Photoforum and Photoworks, 2006), 17.

2. Susan Sontag, On Photography (London: Penguin, 1979), 14-15. 